\title{
Six novel mutations of the LDL receptor gene in FH kindred of Sicilian and Paraguayan descent
}

\author{
ANGELO B. CEFALÙ ${ }^{1}$, GIACOMA BARRACO ${ }^{1}$, DAVIDE NOTO ${ }^{1}$, VINCENZA VALENTI ${ }^{1}$, \\ CARLO M. BARBAGALLO ${ }^{1}$, GERARDO D. ELISIR ${ }^{3}$, LUIS A. CUNIBERTI ${ }^{4}$, \\ JOSÉ P. WERBA ${ }^{5}$, MASSIMO LIBRA ${ }^{6}$, SALVATORE COSTA ${ }^{2}$, FABRIZIO GIANGUZZA ${ }^{2}$, \\ ALBERTO NOTARBARTOLO $^{1}$, SALVATORE TRAVALI ${ }^{6}$ and MAURIZIO R. AVERNA ${ }^{1}$
}

\begin{abstract}
Departments of ${ }^{1}$ Internal Medicine and Geriatrics, ${ }^{2}$ Cellular and Development Biology, University of Palermo, Italy; ${ }^{3}$ Institute of Cardiology and Cardiovascular Surgery, ${ }^{4}$ Lipid and Atherosclerosis Research Laboratory, Department of Pathology, University Dr. Rene G. Favaloro, Favaloro Foundation, Buenos Aires, Argentina; ${ }^{5}$ Centro Cardiologico Monzino, IRCCS, Milan; ${ }^{6}$ Department of Biomedical Sciences, Section of Clinical Pathology and Molecular Oncology, University of Catania, Italy
\end{abstract}

Received October 5, 2005; Accepted November 18, 2005

\begin{abstract}
Familial hypercholesterolemia (FH) is an autosomal dominant inherited disease caused by mutations in the gene coding for the low density lipoprotein receptor (LDL-R). It is characterized by a high concentration of low density lipoprotein (LDL), which frequently gives rise to premature coronary artery disease. We studied the probands of five FH Sicilian families with 'definite' $\mathrm{FH}$ and one proband of Paraguayan descent with homozygous FH who has been treated with an effective living-donor liver transplantation. In order to seek the molecular defect in these six families, we used direct sequencing to define the molecular defects of the LDL-R gene responsible for the disease. We described three novel missense mutations (C100Y, C183Y and G440C), two frameshift mutations (g.1162delC in exon 8 and g.2051delC in exon 14 ) and one mutation ( $\mathrm{g} .2390-1 \mathrm{G} \rightarrow \mathrm{A})$ at splicing acceptor consensus sequences located in intron 16 of the LDL-R gene; the analysis of cDNA of this splicing mutation showed the activation of a cryptic splice site in intron 16 and the binding studies showed a reduction in internalisation of LDL-DIL in the proband's cultured fibroblasts. Moreover, a g.2051delC in exon 14 was identified in the proband of Paraguayan ancestry with clinical features of homozygous FH. The mutation identified in the South American patient represents the first description of a variant in South American patients other than Brazilian FH patients. The 5 mutations identified in the
\end{abstract}

Correspondence to: Dr Maurizio R. Averna, Department of Internal Medicine, University of Palermo, Via del Vespro 141, I-90127 Palermo, Italy

E-mail: avernam@unipa.it

Key words: hypercholesterolemia, LDL receptor gene, mutation analysis, direct sequencing, splicing, living-donor transplantation
Sicilian patients confirm the heterogeneity of LDL-R gene mutations in Sicily.

\section{Introduction}

Familial hypercholesterolemia (FH; MIM \#143890) is an autosomal dominant inherited disease caused by mutations in the gene coding for the low density lipoprotein receptor (LDL-R). LDL-R mediates the specific uptake and catabolism of LDL in the liver and many other tissues (1). Heterozygous carriers of a defective LDL-R gene express only half the number of functional receptors and have markedly raised plasma cholesterol levels that are frequently associated with tendon xanthomata, accelerated atherosclerosis, and premature coronary artery disease $(2,3)$. Homozygous individuals are more severely affected and may die from coronary artery disease before reaching the age of maturity.

The prevalence of heterozygous $\mathrm{FH}$ appears to be $\sim 0.2 \%$ in European and North American populations (4). Except for few populations in which founder mutations have been described, the defects underlying FH are very heterogeneous and each family is a priori expected to present a unique LDL-R mutation (5-7). So far, $>900$ different mutations of the LDL-R gene, largely being point mutations or small deletions and insertions, have been reported (8; http://www. ucl.ac.uk/fh; http://www.umd.necker.fr).

Currently, the diagnosis of FH is generally based on clinical presentation. However, the phenotype of the disease is variable, even among patients with the same genetic mutation, and clinical symptoms of the disease may not always be apparent, especially in young adults and children (9-11). Therefore, a specific molecular diagnosis is desirable in order to stratify the patient's individual risk.

Routinely, laboratory strategies for FH mutation analysis consist of Southern blot analysis and direct sequencing of the whole gene, including the promoter region, the 18 exons and their flanking intron regions. In the present report, we describe 
Family 1

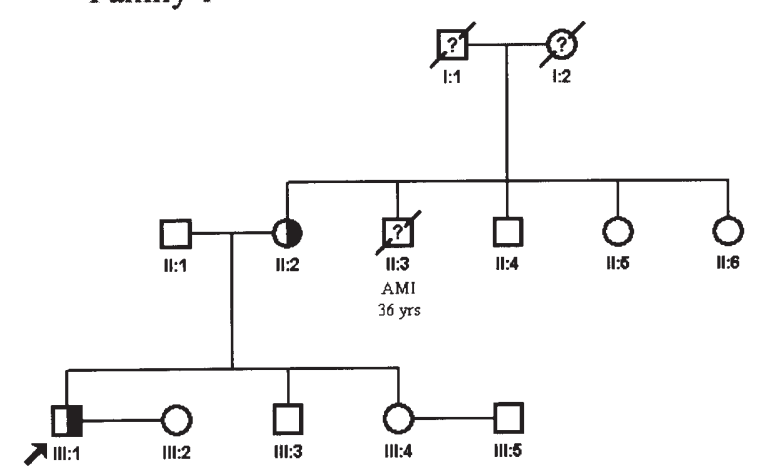

Family 2

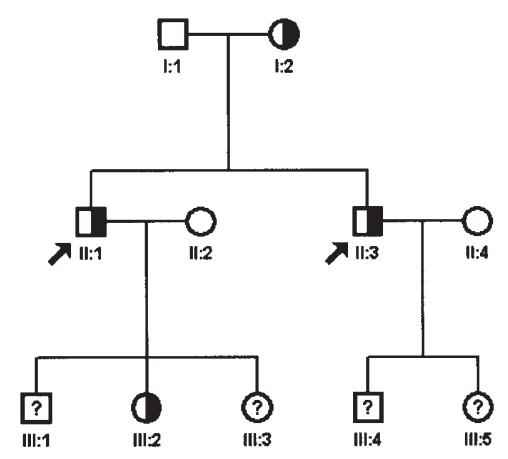

Family 3

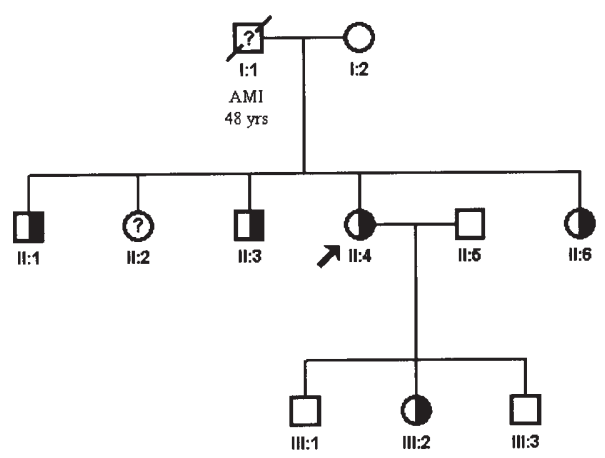

Family 5

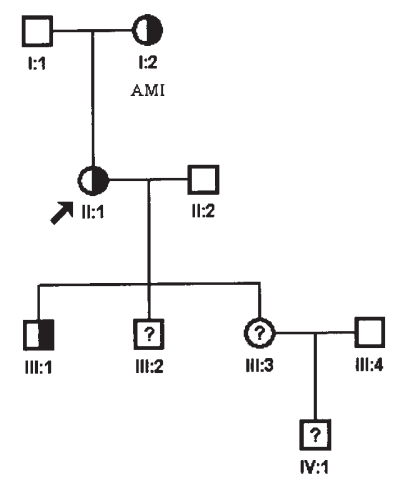

Family 6

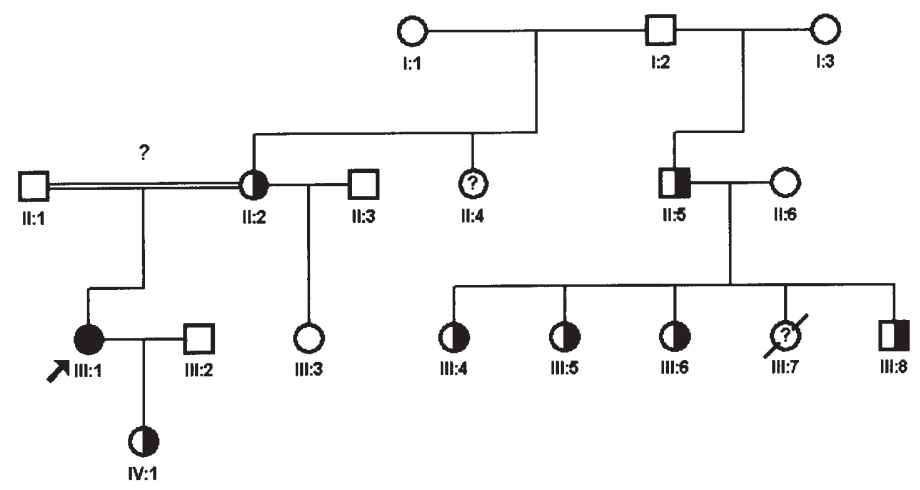

Figure 1. Pedigree of families with familial hypercholesterolemia. Probands are indicated with an arrow. Half-filled symbols, clinically affected subjects diagnosed as FH heterozygote; full symbol, homozygous subject; open symbols, clinically diagnosed non-FH; slashed symbols, deceased individuals; ?, clinical-biochemical data unavailable; AMI, acute myocardial infarction. Probands and available subjects have been characterized by direct sequencing of the entire coding exons and flanking intron sequences.

the identification of six novel mutations in the LDL-R gene in five Sicilian families and in a family from Argentina.

\section{Materials and methods}

Subjects and pedigrees. The probands of five Sicilian FH families were referred to the Lipid Disorders Clinic at the University Hospital of Palermo for investigation. The diagnosis of 'definite' familial hypercholesterolemia was based on the criteria of the Simon Broom Register (9) and on the exclusion of secondary hypercholesterolemia causes.

The DNA from a proband of Paraguayan descent living in Argentina with clinically diagnosed homozygous FH was analysed in order to seek the molecular defect.

Informed consent was obtained from all subjects investigated. The study protocol was approved by the institutional human investigation committee of each participating institution. Pedigrees are shown in Fig. 1. 
Family 1: the proband (III.1) was a 40-year-old Caucasian Sicilian male with severe hypercholesterolemia (total cholesterol $=9.04 \mathrm{mmol} / \mathrm{l})$. On clinical examination no xanthelasmas or tendon xanthomas were present. Ultrasound examination revealed an increase of the carotid intima-media thickness (IMT). The proband reported that his mother suffered of hypercholesterolemia and coronary artery disease and died at the age of 42 years after coronary artery bypass surgery; moreover, an uncle (II.3) died at the age of 36 years of acute myocardial infarction. No other family members were reported to have hypercholesterolemia.

Family 2: two brothers, 36 and 33 years old (II.1 and II.3), were referred to us with hypercholesterolemia (total cholesterol $=7.7$ and $7.5 \mathrm{mmol} / \mathrm{l}$, respectively). On clinical examination, no xanthelasmas or tendon xanthomas were present. Ultrasound examination of carotid arteries did not reveal significant alterations of the arterial wall. The 12-yearold daughter of proband II.1 (III.2) showed high cholesterol levels $(6.8 \mathrm{mmol} / \mathrm{l})$. The administration of simvastatin to II.1 and II.3 at a dose of $20 \mathrm{mg} /$ die resulted in a significant reduction of total cholesterol.

Family 3: the proband (II.4) was a 37-year-old Caucasian Sicilian female (total cholesterol $=9.0 \mathrm{mmol} / \mathrm{l}$ ), who reported two brothers (II.1 and II.3) and one sister (II.6) with hypercholesterolemia; the father (I.1) died of AMI at the age of 48 years. The 8 -year-old daughter (III.2) also had hypercholesterolemia $(9.7 \mathrm{mmol} / \mathrm{l})$. Both the proband and her daughter did not have xanthelasmas or tendon xanthomas and ultrasound of carotid arteries did not document the presence of plaques. During the last year, II.4 has been treated with atorvastatin $(10 \mathrm{mg} / \mathrm{die})$ and III.2 with cholestiramine $6 \mathrm{~g} / \mathrm{die}$; these treatments resulted in a reduction of total cholesterol and LDL-C levels. After informed consent, a skin biopsy was obtained from II.4 for LDL binding studies.

Family 4: a 12-year-old Caucasian Sicilian boy (III.3) was referred to the Lipid Clinic for hypercholesterolemia (total cholesterol $=7.8 \mathrm{mmol} / \mathrm{l}$ ). The 44-year-old father (II.3), who was tested afterwards, also showed high plasma total cholesterol levels $(8.2 \mathrm{mmol} / \mathrm{l})$; he had been smoking approximately 20 cigarettes/day for 20 years. On clinical examination, none of them were found to have xanthelasmas or tendon xanthomas. Ultrasound examination of the carotid arteries of subject II.3 revealed significant alterations of the arterial wall characterised by diffuse IMT increase and the presence of plaques $(1.9 \mathrm{~mm}$ in the right bifurcation and $1.7 \mathrm{~mm}$ in the left one). II.3 also reported to have one brother (II.1), one sister (II.5) and one niece (III.6) with hypercholesterolemia and his father (I.1) died of myocardial infarction.

Family 5: a 54-year-old Caucasian Sicilian female (II.1) was referred to the Lipid Clinic for hypercholesterolemia (total cholesterol $=8.9 \mathrm{mmol} / \mathrm{l}$ ). The proband's mother $(\mathrm{I} .2)$ was also hypercholesterolemic and suffered a myocardial infarction. One of the sons (III.1), 21 years old, was tested afterwards and showed high plasma total cholesterol levels (9.0 mmol/1). On clinical examination, none of them were found to have xanthelasmas or tendon xanthomas. Ultrasound examination of the carotid arteries of subject II.1 revealed significant alterations of the arterial wall, characterised by diffuse IMT increase and the presence of plaques (1.9 $\mathrm{mm}$ in the left bifurcation and $40 \%$ stenosis of the left internal carotid artery). The ultrasound of the carotid arteries of subject III.1 did not document any IMT alteration or plaques. Treatment with atorvastatin at $20 \mathrm{mg} /$ die was begun.

Family 6: proband (III.1) was a 28-year-old Argentine female patient of Paraguayan ancestry, who was referred to the Favaloro Foundation, Buenos Aires, with chest pain. Since the age of 4 years, she had had planar xanthomata, she was referred with a total serum cholesterol $>25.8 \mathrm{mmol} / \mathrm{l}$ and, at the age of 21 years, had been diagnosed with aortic valve sclerosis. Upon physical examination, she had arcus corneale, extensive xanthomata and aortic insufficiency. Her lipid profile showed severe hypercholesterolemia (total cholesterol $=18.5$ and LDL-C $=17.3 \mathrm{mmol} / \mathrm{l})$, refractory to therapy with atorvastatin $(80 \mathrm{mg} /$ day $)$ plus cholestyramine $(12 \mathrm{~g} /$ day $)$. Ultrasound examination showed stenosis of carotid arteries and a coronary angiography evidenced critical stenosis of coronary arteries. In August 2000, based on the clinical diagnosis of definite homozygous $\mathrm{FH}$ and the rapid progression of vascular disease, a living-donor liver transplantation was performed; her presumably half-sister (III.3) was accepted as a donor. The patient's lipid profile normalized immediately.

The proband's 7-year-old daughter (IV.1) had high total cholesterol levels $(9.0 \mathrm{mmol} / \mathrm{l})$. The proband reported also that her mother (II.2) had hypercholesterolemia, tendinous xanthomas and coronary artery disease; moreover, an uncle (II.5), with total cholesterol levels of approximately $11.7 \mathrm{mmol} / \mathrm{l}$, had four of five children which showed severe hypercholesterolemia. Other family members were referred to have hypercholesterolemia (see the genealogical tree in Fig. 1).

The identity of the proband's father (II.1) was uncertain, but horizontal consanguinity was suspected. Among the family members, we were able to obtain DNA samples for molecular studies from the proband (III.1), her mother (II.2), her halfsister (III.3) and her daughter (IV.1).

Blood sampling, DNA isolation and biochemical analysis. Blood samples were collected from probands and available family members after an overnight fast. Blood was collected in a plain tube and in a ethylenediaminetetraacetic acid (EDTA) tube to separate serum and plasma, respectively. Plasma total cholesterol, high density lipoprotein (HDL) cholesterol and triglyceride were measured enzymatically on a Mira Plus automatic analyser (Roche Diagnostics, Italy). LDL-cholesterol concentrations were calculated using the equation of Friedewald et al (12). EDTA blood samples were also used for DNA isolation.

Polymerase chain reaction and direct sequencing of the $L D L-R$ gene. To screen for small deletions, insertions or point mutations in the LDL-R gene, direct sequencing of PCR amplified genomic regions was performed. Briefly, genomic DNA was amplified using specific primers for each of the 18 exons encompassing the coding sequences and the splice site consensus at the intron/exon junctions of the LDL-R gene. Together with exon 1, $300 \mathrm{bp}$ of the promoter region were analyzed. PCR fragments were purified using a commercial kit (Wizard PCR Preps DNA Purification System; Promega Italia, Italy) and sequenced directly in both directions using a Big-Dye Terminator cycle sequencing kit 1.1 (Applied Biosystems, Foster City, CA, USA); samples were then 
Table I. Plasma lipid concentrations and clinical characteristics.

\begin{tabular}{|c|c|c|c|c|c|c|c|c|}
\hline Subject & $\begin{array}{c}\text { LDL-R } \\
\text { Gene mutation }\end{array}$ & $\begin{array}{c}\text { Age } \\
\text { (years) }\end{array}$ & Sex & $\begin{array}{c}\mathrm{TC} \\
(\mathrm{mmol} / \mathrm{l})\end{array}$ & $\begin{array}{c}\text { LDL-C } \\
(\mathrm{mmol} / \mathrm{l})\end{array}$ & $\begin{array}{l}\text { HDL-C } \\
(\mathrm{mmol} / \mathrm{l})\end{array}$ & $\begin{array}{c}\mathrm{TG} \\
(\mathrm{mmol} / \mathrm{l})\end{array}$ & CVD \\
\hline \multicolumn{9}{|l|}{ Family 1} \\
\hline III.1 & g.1162delC & 40 & $\mathrm{M}$ & 9.04 & 7.78 & 1.1 & 0.8 & \\
\hline \multicolumn{9}{|l|}{ Family 2} \\
\hline I. 1 & W & 57 & $\mathrm{M}$ & 5.5 & 3.6 & 0.7 & 2.7 & \\
\hline I. $2^{\mathrm{a}}$ & g. $362 \mathrm{G} \rightarrow \mathrm{A}$ & 54 & $\mathrm{~F}$ & 5.7 & 4.3 & 0.9 & 1.0 & \\
\hline II.1 & g. $362 \mathrm{G} \rightarrow \mathrm{A}$ & 36 & M & 7.7 & 7.2 & 0.4 & 0.5 & \\
\hline II. 3 & g. $362 \mathrm{G} \rightarrow \mathrm{A}$ & 33 & $\mathrm{M}$ & 7.5 & 6.4 & 0.7 & 2.0 & \\
\hline III. 2 & g. $362 \mathrm{G} \rightarrow \mathrm{A}$ & 12 & $\mathrm{~F}$ & 6.8 & 5.4 & 1.3 & 0.7 & \\
\hline \multicolumn{9}{|l|}{ Family 3} \\
\hline II.4 & g. $2390-1 \mathrm{G} \rightarrow \mathrm{A}$ & 37 & $\mathrm{~F}$ & 9.0 & 7.5 & 1.4 & 0.4 & \\
\hline II. 5 & W & 42 & $\mathrm{M}$ & 5.3 & 3.8 & 1.2 & 0.7 & \\
\hline III.1 & $\mathrm{W}$ & 5 & M & 4.2 & 3.7 & 0.6 & 0.7 & \\
\hline III. 2 & g. $2390-1 \mathrm{G} \rightarrow \mathrm{A}$ & 8 & $\mathrm{~F}$ & 9.7 & 8.5 & 0.8 & 0.9 & \\
\hline \multicolumn{9}{|l|}{ Family 4} \\
\hline II. 2 & $\mathrm{~W}$ & 43 & $\mathrm{~F}$ & 5.8 & 3.4 & 2.0 & 0.9 & \\
\hline II. 3 & g. $1381 \mathrm{G} \rightarrow \mathrm{T}$ & 46 & $\mathrm{M}$ & 8.2 & 6.8 & 1.0 & 1.9 & CA \\
\hline III. 3 & g. $1381 \mathrm{G} \rightarrow \mathrm{T}$ & 12 & $\mathrm{M}$ & 7.8 & 5.4 & 1.9 & 1.0 & \\
\hline \multicolumn{9}{|l|}{ Family 5} \\
\hline II.1 & g. $611 \mathrm{G} \rightarrow \mathrm{A}$ & 54 & $\mathrm{~F}$ & 8.9 & 6.8 & 1.0 & 2.3 & CA \\
\hline III.1 & g. $611 \mathrm{G} \rightarrow \mathrm{A}$ & 21 & M & 9 & 7.6 & 0.8 & 1.3 & \\
\hline \multicolumn{9}{|l|}{ Family 6} \\
\hline II. 2 & g.2051delC & 49 & $\mathrm{~F}$ & 9.3 & 7.5 & 1.1 & 1.6 & CAD \\
\hline II.5 & W & - & $\mathrm{F}$ & 5.2 & 3.0 & 1.1 & 2.5 & \\
\hline III.1 & g.2051 delC ${ }^{b}$ & 28 & $\mathrm{~F}$ & 18.5 & 17.3 & 0.7 & 1.2 & DA \\
\hline IV.1 & g.2051delC & 7 & $\mathrm{~F}$ & 9.0 & 7.6 & 1.1 & 1.6 & \\
\hline
\end{tabular}

TC, total cholesterol; TG, triglycerides; CVD, cardiovascular disease; CA, carotid atherosclerosis; CAD, coronary artery disease; DA, diffuse

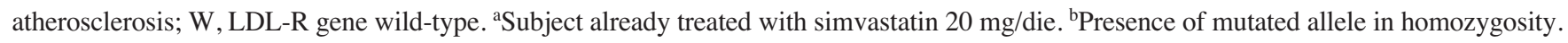

analysed on an ABI PRISM 310 automated DNA sequencing device (Applied Biosystems).

Fibroblast cultures and isolation of $m R N A$. Skin biopsies were taken from the proximal part of the volar side of the forearm. Fibroblasts were grown as monolayer in a $5 \% \mathrm{CO}_{2} /$ air mixture, humidified at $37^{\circ} \mathrm{C}$; the culture medium was Dulbecco's modified Eagle's medium (DMEM glutamax, Invitrogen, Grand Island, NY, USA) supplemented with $10 \%$ (v/v) fetal bovine serum, $100 \mathrm{U} / \mathrm{ml}$ penicillin, $100 \mu \mathrm{g} / \mathrm{ml}$ streptomycin, and $1 \%$ non-essential amino acids (Invitrogen).

Cells, at their 3th passage, were harvested and mRNA was isolated using a standard procedure (RnaWiz, Ambion, UK) and resuspended in diethyl pyrocarbonate-treated water. The preparation was checked for integrity by agarose gel electrophoresis and quantitated by reading at $260 \mathrm{~nm}$ (BioPhotometer, Eppendorf, Germany).

LDL binding assay. Skin fibroblasts (HSFs) from the proband (II.4, family 3 ) and from a normal subject were cultured as described above. LDL labelled with the fluorescent dye dioctadecyl-indo-carbocyanine iodide (DIL; Sigma Aldrich, Italy) were prepared as described elsewhere (13). Approximately 75,000 human skin fibroblasts/well were seeded in 24-well plates (Corning Life Sciences, MA, USA) and grown to subconfluence. Forty-eight hours before the binding experiment, culture medium was replaced with $1 \mathrm{ml}$ of DMEM supplemented with $10 \%$ lipoprotein depleted serum (LPDS), to overexpress cell LDL receptors. Monolayers were washed twice with PBS and incubated for $4 \mathrm{~h}$ with increasing amounts of DIL-LDL (from 0 to $120 \mu \mathrm{g} / \mathrm{ml}$ ) alone or competed with a 50-fold excess of the same cold LDL fractions, in order to evaluate the non-specific fluorescence background. After three washes with cold PBS supplemented with $2 \mathrm{mM}$ $\mathrm{CaCl}_{2}$ plus $2 \mathrm{mM} \mathrm{MgCl}$, cells were lysed in $0.1 \mathrm{~N} \mathrm{NaOH}$, $0.1 \% \mathrm{SDS}$ at $37^{\circ} \mathrm{C}$ for $1 \mathrm{~h}$. Aliquots were used for protein determinations (BCA micro; Pierce Biotechnology, Rockford, IL, USA) and cell incorporated fluorescence was read on an RXL10 Shimadzu fluorimeter (Shimadzu Corporation, Tokyo, Japan) at EX $535 \mathrm{~nm}$ and EM $570 \mathrm{~nm}$. DIL-LDL incorporation was calibrated against a DIL-LDL scale in the same lysis buffer. Results were expressed as nanograms of incorporated 
A

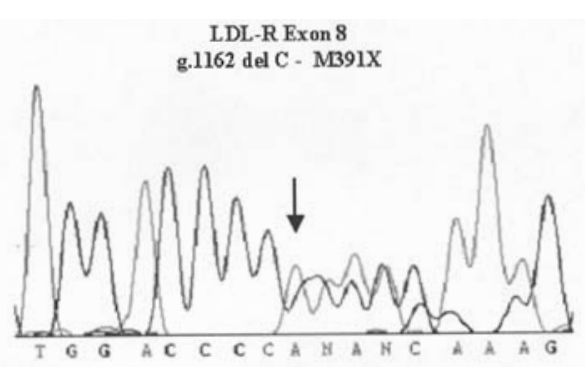

B

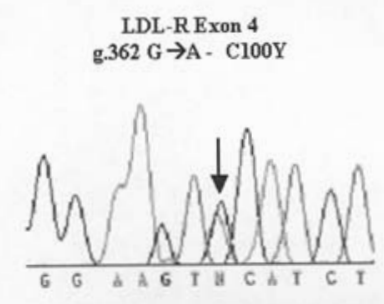

$\mathrm{C}$

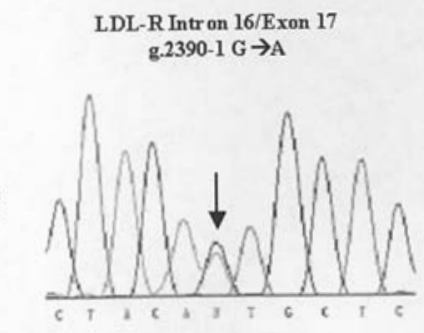

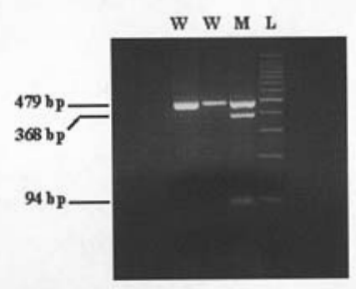

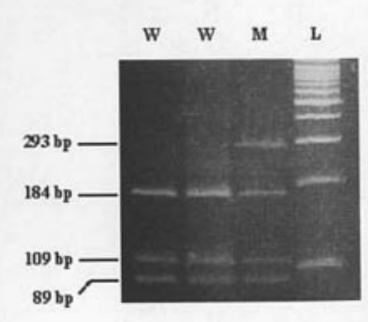

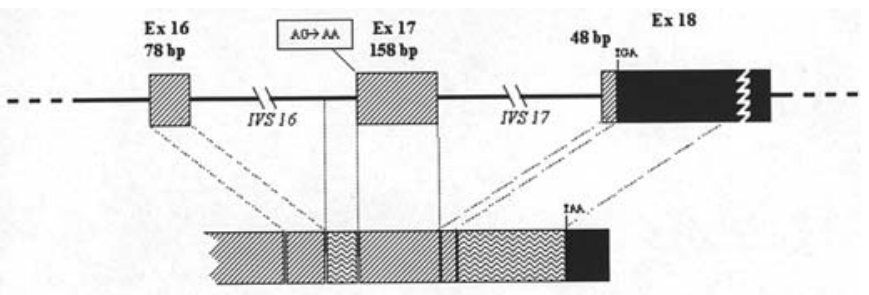

1

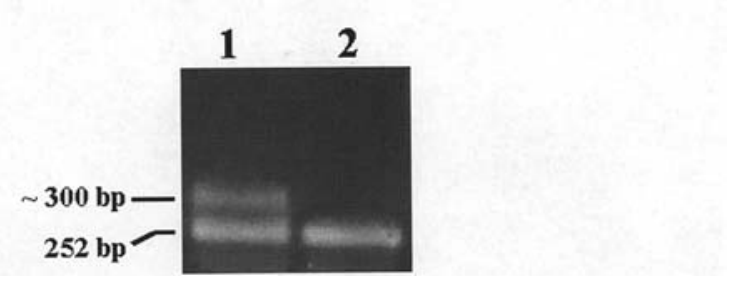

2

Figure 2. Analysis of the LDL-R gene in families 1, 2 and 3. (A) Partial sequence of exon 8 in the proband of family 1 . The nucleotide $\mathrm{C}$ deletion, shown by the arrow, causes a frameshift in one allele. (B) Partial sequence of exon 4 in a proband of family 2 ; the arrow indicates the $\mathrm{G} \rightarrow \mathrm{A}$ transition. On the right, the results of the screening for mutation, based on PCR amplification and RsaI enzymatic digestion of exon 4, is shown. (C) Sequence of the intron 16/exon 17 junction in the proband of family 3 . On the right, AocII restriction map of the amplicon spanning the mutation site in the mutant allele. M, carrier of the mutant allele in heterozygosity; W, wild-type allele; L, 100-bp ladder.

DIL-LDL/mg of cell proteins. All experiments were performed in triplicate.

Reverse transcription-polymerase chain reaction ( $R T-P C R)$ and $c D N A$ sequencing. mRNA prepared from WT fibroblasts and white blood cells from the subject II.4 of family 3 were studied. One $\mu \mathrm{g}$ of total RNA was reverse transcribed using an antisense primer (20 pmol) localized in exon 18 of the LDL-R cDNA sequence at position 2643-2623 (5'-TCAT CCTCCAGACTGACCATC-3'; GeneBank Accession no. $\mathrm{BC} 014514)$ in a $20 \mu 1$ total volume reaction mixture, containing $1.5 \mu \mathrm{l}$ of $50 \mathrm{mM} \mathrm{MgCl} \mathrm{Mg}_{2}, 2 \mu \mathrm{l}$ of 10X PCR buffer, $2 \mu \mathrm{l}$ each of $10 \mathrm{mM}$ dNTP, $0.5 \mu 1$ of RNase inhibitor (Promega Italia). The mixture was incubated at $70^{\circ} \mathrm{C}$ for $10 \mathrm{~min}$, cooled down to $40^{\circ} \mathrm{C}$ and $1 \mu \mathrm{l}(10 \mathrm{U})$ of M-MLV reverse transcriptase (Promega Italia) was added. The reaction was carried out for $30 \mathrm{~min}$ and after denaturation at $95^{\circ} \mathrm{C}$ for $5 \mathrm{~min}$, the PCR reaction was settled. For the PCR reaction, the following ingredients were added to the above reaction mixture: $1.5 \mu 1$ of $\mathrm{MgCl}_{2}(50 \mathrm{mM}), 8 \mu \mathrm{l}$ of $10 \mathrm{X}$ PCR buffer, $68 \mu 1$ of sterile

Figure 3. Upper panel, schematic representation of the LDL-R gene encompassing exons 16 through 18 (up) and mRNA structure of the splicing variant when $\mathrm{g} .2390-1 \mathrm{G} \rightarrow \mathrm{A}$ is present. The mutated splice acceptor consensus and the normal and novel stop codons are indicated. Lower panel, reverse transcriptase-PCR analysis of LDL-R mRNA region coding for exons 16-18. RNA from normo-cholesterolemic generate an amplification product of 252 bp (lane 1), while RNA extracted from HSF of proband II.4, family 3, shows the wild amplicon and a longer product of approximately $300 \mathrm{bp}$ (lane 2).

water, $2 \mu 1(20 \mathrm{pmol})$ of forward primer in exon 16 at position 2413-2431 (5'-ACGTTGCTGGCAGAGGAA-3'; GeneBank Accession no. BC014514), and $0.5 \mu 1$ (2.5 U) of TaqDNA polymerase. Thirty cycles of PCR were performed using the following profile: $95^{\circ} \mathrm{C}$ for $60 \mathrm{sec}, 56^{\circ} \mathrm{C}$ for $60 \mathrm{sec}$, and $72^{\circ} \mathrm{C}$ for $60 \mathrm{sec}$, with a final elongation step at $72^{\circ} \mathrm{C}$ for $7 \mathrm{~min}$. PCR products were separated by electrophoresis on a $1.5 \%$ agarose gel and the different fragments were excised and purified using the Wizard PCR Preps DNA purification system (Promega Italia) for sequencing analysis.

\section{Results}

Plasma lipid concentrations and clinical characteristics of the members of the six families studied are shown in Table I.

Family 1. The sequence of the LDL-R gene revealed a single nucleotide deletion in exon $8 \mathrm{~g} .1162 \mathrm{delC}$ (Fig. 2A) responsible for a frameshift with an expected premature stop codon (M391X).

Family 2. The sequence of the LDL-R gene revealed a $\mathrm{G} \rightarrow \mathrm{A}$ transition in exon 4 g.362G $\rightarrow$ A (Fig. 2B), responsible for a single amino-acid substitution in position 100 of LDL-R $(\mathrm{C} 100 \mathrm{Y})$. The mutation is present in heterozygosity in the four hypercholesterolemic subjects of this family. The mutation in the affected individuals creates a consensus sequence for the restriction endonuclease, RsaI. Consequently, a simple, reliable PCR-based screening technique could detect the $\mathrm{G} \rightarrow \mathrm{A}$ substitution at codon 100 . This approach involved RsaI restriction digestion (Fermentas, Italy) of a 479-bp region of exon 4 spanning the mutated codon and subsequent analysis by $2 \%$ agarose gel electrophoresis (Fig. 2B).

Family 3. The direct sequence of amplified product including exon 17 and splice site sequences at the intron/exon junction 


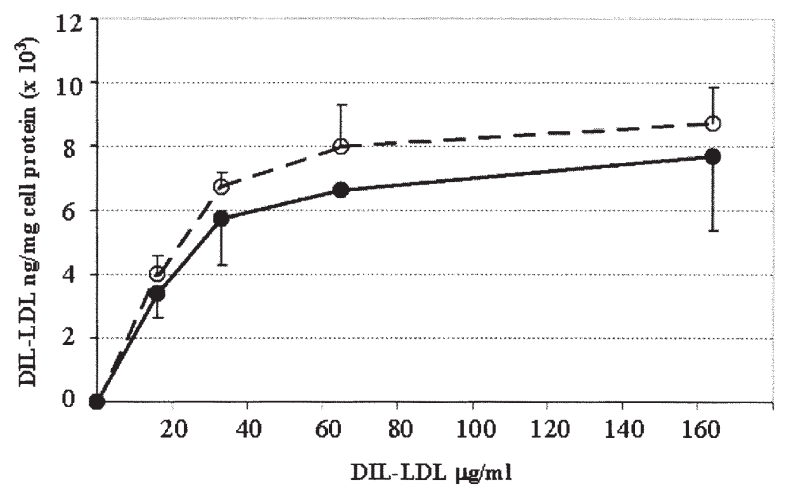

Figure 4. Representative binding assay showing total and non-specific LDL receptor internalization of DIL-LDL in fibroblasts isolated from the proband of family 3 with the $\mathrm{g} .2390-1 \mathrm{G} \rightarrow \mathrm{A}$ mutation and a clinically unaffected normal control. LDL internalization was measured as described in Materials and methods. Control, $-\bullet-\cdots$ proband, $-\bullet$. Vmax proband $/ \mathrm{Vmax}$ control = $0.87 ; \mathrm{kd}$ proband $/ \mathrm{kd}$ control $=1.08$.

revealed a $\mathrm{G} \rightarrow \mathrm{A}$ transition in the ultimate 3 '-nucleotide of intron 16, g.2390-1G $\rightarrow$ A (Fig. 2C), thus, altering the 3'-splice acceptor AG dinucleotide to AA. As this mutation abolishes an AocII restriction site, a 382-bp PCR fragment encompassing the mutated site was digested with AocII (Fermentas, Italy) and the digestion products were separated on $2 \%$ agarose gel (Fig. 2C). This splicing mutation was further evaluated to investigate the effect on the processing of LDL receptor mRNA. RT-PCR analysis was performed with primers designed to selectively amplify the coding sequence spanning exons 16-18. As shown in Fig. 3, RNA from WT fibroblasts gives a single band of the expected size of 252 bp (lane 2), while RNA from proband's fibroblasts (lane 1) shows two products, one corresponding to the wild-type messenger (252 bp) and a novel fragment of approximately $300 \mathrm{bp}$. Sequence analysis of this fragment revealed that the g.2390$1 \mathrm{G} \rightarrow \mathrm{A}$ substitution at the $3^{\prime}$ acceptor splice site of intron 16 alters the consensus sequence for splicing and is responsible for retention of 62 nucleotides of intron 16 in the transcript, between exons 16 and 17 in the mutant mRNA (Fig. 3). Therefore, the predicted polypeptide will contain normally translated amino acids encoded by exon 16 which is followed by 21 new amino acids encoded by intron 16 and by outframe amino acids encoded by exons 17 and 18; this insertion leads to a new stop codon (TAA) in exon 18, 210 nucleotides downstream of the TGA stop codon present in the normal sequence. The results of the LDL internalisation experiment are presented in Fig. 4. Human fibroblasts were cultured from skin biopsies obtained from the proband and a normal subject. HSFs were tested for their ability to bind and internalise increasing amounts of fluorescent LDLs. The data were modelled with the first order Michaelis-Menten equation; proband fibroblasts showed a reduced Vmax (87\%) vs. control fibroblasts, while dissociation constants $(\mathrm{kd})$ were similar (proband $\mathrm{kd}=108 \%$ of control $\mathrm{kd}$ ).

Family 4. The sequence of the LDL-R gene revealed a single nucleotide change in exon $10 \mathrm{~g} .1381 \mathrm{G} \rightarrow \mathrm{T}$ (Fig. 5A), responsible for an amino-acid change (G440C). The mutation abolished a restriction site for the restriction endonuclease,
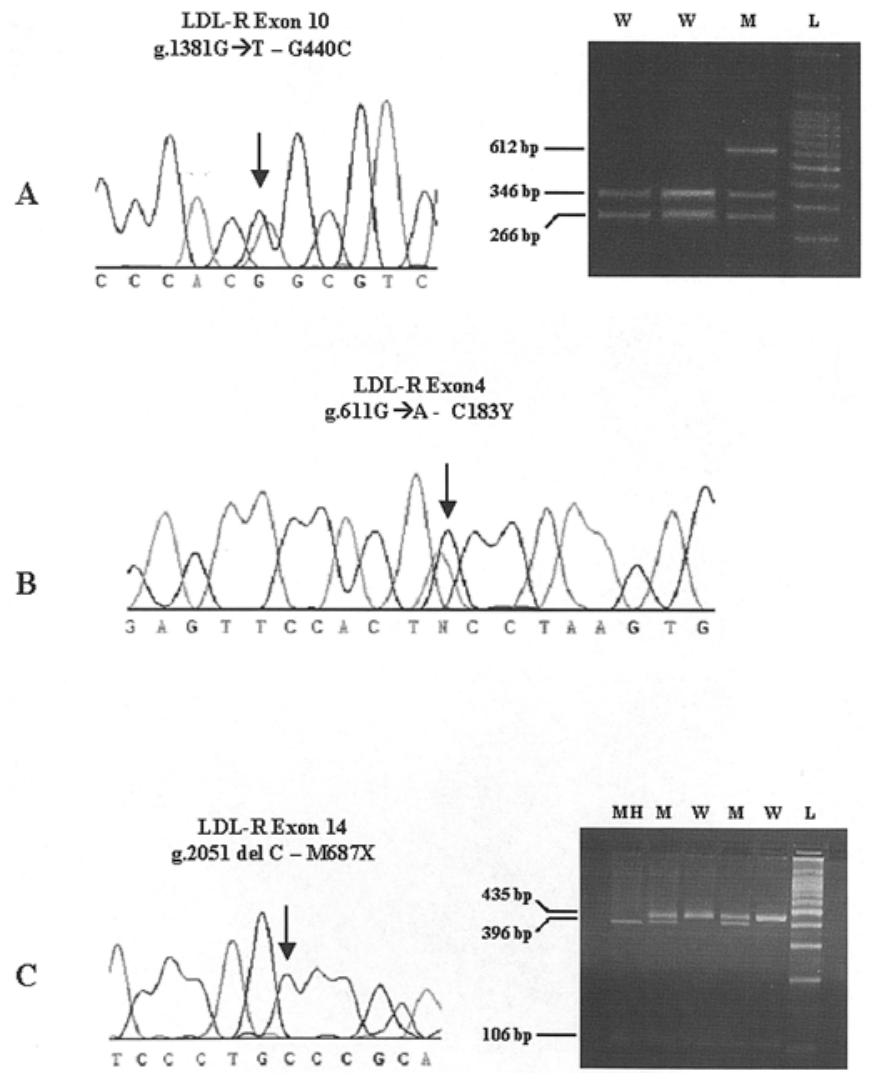

Figure 5. Analysis of the LDL-R gene in families 4, 5 and 6. (A) Partial sequence of exon 10 in the proband of family 4 , showing a $\mathrm{G} \rightarrow \mathrm{T}$ transversion with amino-acid substitution in codon 440. Following the PCR reaction, digestion of exon 10 product from the heterozygote proband using the restriction enzyme, AcyI, is clearly resolved from the wild-type PCR product by electrophoresis on $2 \%$ agarose gel. (B) Partial sequence of exon 4 in the proband of family 5 demonstrates a $\mathrm{G} \rightarrow \mathrm{A}$ transition causing an amino-acid change. In the mutant allele, the substitution at codon 183 creates a recognition site for BstI; endonuclease cleavage of exon 4 amplicons with BstI is diagnostic for the mutation. (C) Partial sequence of exon 14 in the proband of family 6 shows a single cytidine deletion in homozygosis. On the right, the results of screening for mutation, based on PCR amplification and Cac8I enzymatic digestion of exon 14, is shown. M, carrier of the mutant allele in heterozygosity; $\mathrm{MH}$, carrier of the mutant allele in homozygosity; W, wild-type allele; L, 100-bp ladder.

AcyI. By digestion of a 612-bp PCR fragment of exon 10 encompassing the mutated site with AcyI (Fermentas), followed by product separation on $2 \%$ agarose gel (Fig. 5A), it is possible to distinguish between carriers and normal individuals.

Family 5. The sequence of the LDL-R gene revealed a $\mathrm{G} \rightarrow \mathrm{A}$ transition in exon 4 g.611G $\rightarrow$ A (Fig. 5B), responsible for a single amino-acid substitution in position 183 of LDL-R (C183Y). The mutation is present in heterozygosity in the two hypercholesterolemic subjects. This mutation moves a restriction site for the restriction endonuclease, BstI (data not shown).

Family 6. The sequence of the LDL-R gene revealed a homozygous single nucleotide deletion in exon $14 \mathrm{~g} .2051 \mathrm{delC}$ (Fig. 5C), responsible for a frameshift with an expected premature stop codon (M687X). The direct sequence of exon 14 of the LDL-R gene of the proband's mother and daughter 
showed the presence of the g.2051delC mutation in heterozygosity, while the unaffected half-sister did not show the same mutation. A rapid test for the detection of the mutation was developed based on the creation of a Cac8I site in the mutated allele. Mutant and wild-type DNA can be distinguished by resolving the Cac8I digestion products of a 612-bp PCR fragment encompassing the mutated site on exon 14 , on $2 \%$ agarose gel (Fig. 5C).

\section{Discussion}

In this report, we describe 5 novel mutations in the LDL-R gene that were associated with a phenotype of heterozygous familial hypercholesterolemia and 1 novel mutation detected in a homozygous FH patient.

We have analyzed the promoter region and the 18 exons and their flanking intron sequences of the LDL-R gene in each subject; the mutations described are the only sequence variations identified in the entire gene. Moreover, these nucleotide variations are expected to be the disease causing mutations because the co-segregation of the mutant allele with the phenotype of familial hypercholesterolemia has been demonstrated in all studied families.

Three missense mutations were found. Two of them (C100Y and $\mathrm{C} 183 \mathrm{Y}$ ) were in the ligand binding domain of LDL-R, one (G440C) was in the epidermal growth factor (EGF) precursor homology domain. Although expression of the mutant genes and functional studies of the encoded receptors have not been performed yet, we believe that the causative significance of these mutations is supported. The $\mathrm{C} 100 \mathrm{Y}$ and the $\mathrm{C} 183 \mathrm{Y}$ mutations concern two amino acids conserved among different animal species and neither of the three variants were found in 50 unrelated control subjects (100 chromosomes).

The two frameshift mutations identified (g.1162delC of exon 8 and g.2051delC in exon 14) result in the creation of premature stop codons at 25 and 24 codons downstream of the deletion sites, respectively, and these mutant alleles are predicted to code for truncated LDL-R proteins of 391 and 687 amino acids, respectively.

We found one novel mutation (g.2390-1G $\rightarrow$ A) at splicing acceptor consensus sequences located in intron 16 of the LDL$\mathrm{R}$ gene. This base substitution changes the highly conserved dinucleotides AG in AA. Different mutations at this consensus sequence have been previously described $(14,15)$. Analysis of the mutant mRNA showed the activation of a cryptic splice site in intron 16, causing the inclusion of 62 new nucleotides, spanning the 3 '-end of intron 16 and the alteration of the correct reading frame, with a TAA stop codon 210 nucleotides downstream of the normal TGA stop codon in exon 18. The mutant LDL receptor protein will then present an elongation of 90 amino acids.

The mutation should affect two of the functional domains of the LDL receptor: the membrane spanning domain and the cytoplasmic domain. Binding studies showed a reduction in internalisation of LDL-DIL in cultured fibroblasts of the proband.

The g.2051delC in exon 14 was identified in a 28 -year-old proband of Paraguayan ancestry who was first referred to the Favaloro Foundation, Buenos Aires, for coronary artery disease and clinical features of homozygous familial hypercholesterolemia. As far as we know, except for mutations in the LDL-R gene responsible for FH in Brazilian subjects $(16,17)$, this is the first report of mutation in a patient from South America.

Traditionally, treatment options for homozygous familial hypercholesterolemia are considered apheresis and plasmapheresis (18), but liver transplantation has to be considered in selected cases of severe homozygous FH (19-21).

In our homozygous FH patient, a living-donor liver transplantation using a full right lobe was effective and lipid lowering drugs have not been required so far. Four years after liver transplantation, the patient is asymptomatic, gainfully employed, with normal liver and cardiac function.

In conclusion, we describe 6 novel mutations of the LDL-R gene responsible for familial hypercholesterolemia. The mutation identified in the South American patient represents the first description of a variant in South American patients other than Brazilian FH patients $(16,17)$. The 5 mutations identified in the Sicilian patients demonstrate and confirm the heterogeneity of LDL-R gene mutation in Sicilian patients with a clinical diagnosis of $\mathrm{FH}$.

\section{Acknowledgements}

This study was supported by University of Palermo, Italy; contract grant number: ' $60 \%$ ' to A.N., C.M.B. and M.R.A.

\section{References}

1. Goldstein JL and Brown MS: Familial hypercholesterolaemia. In: The Metabolic Basis of Inherited Disease. Scriver CR et al (eds). McGraw Hill, New York, pp1215-1245, 1995.

2. Slack J: Risks of ischaemic heart-disease in familial hyperlipoproteinaemic states. Lancet ii: 1380-1382, 1969.

3. Stone NJ, Levy RI, Fredrickson DS and Verter J: Coronary artery disease in 116 kindred with familial type II hyperproteinemia. Circulation 49: 476-488, 1974.

4. Hobbs HH, Russell DW, Brown MS and Goldstein JL: The LDL receptor locus in familial hypercholesterolemia: mutational analysis of a membrane protein. Annu Rev Genet 24: 133-170, 1990.

5. Marino G, Travali S, Reyes T, Fallace BR, Caldarella R, Travali S, Emmanuele G, Stivala F, Barbagallo CM, Cantafora A, Bertolini S, Notarbartolo A and Averna M: Rapid screening of the LDL receptor point mutation FHGenoa/Palermo Human Mutation. Mutation in Brief \#238 online, 1999

6. Marks D, Wonderling D, Thorogood M, Lambert H, Humphries SE and Neil HAW: Screening for hypercholesterolaemia versus case finding for familial hypercholesterolaemia: systematic review and cost effectiveness analysis. Health Technol Assess 4: 1-123, 2000.

7. Bertolini S, Cantafora A, Averna M, Cortese C, Motti C, Martini S, Pes G, Postiglione A, Stefanutti C, Blotta I, Pisciotta L, Rolleri M, Langheim M, Ghibellini M, Rabbone I and Calandra S: Clinical expression of familial hypercholesterolemia in clusters of mutations of the LDL receptor gene that cause a receptordefective or receptor-negative phenotype. Arterioscler Thromb Vasc Biol 20: E41-E52, 2000.

8. Heath KE, Gahan M, Whittall RA and Humphries SE: Lowdensity lipoprotein receptor gene (LDLR) world-wide website in familial hypercholesterolaemia: update, new features and mutation analysis. Atherosclerosis 154: 243-236, 2001.

9. Scientific Steering Committee on behalf of the Simon Broome Register Group: Risk of fatal coronary heart disease in familial hypercholesterolaemia. BMJ 303: 893-896, 1991.

10. Durrington PN (ed): Familial hypercholesterolaemia. In: Hyperlipidaemia: Diagnosis and Management. Butterworth-Heinemann Ltd., Oxford, pp108-140, 1995. 
11. WHO: Human Genetics, DoNDP, Familial Hypercholesterolaemia-Report of a Second WHO Consultation. WHO, Geneva, 1999.

12. Friedewald WT, Levi RI and Fredrickson DS: Estimation of the concentration of low density lipoprotein cholesterol concentration in plasma without use of preparative ultracentrifuge. Am J Hum Genet 18: 499-502, 1972.

13. Corsetti JP, Weidner CH, Cianci J and Sparks CE: The labeling of lipoproteins for studies of cellular binding with a fluorescent lipophilic dye. Anal Biochem 195: 122-128, 1991.

14. Cenarro A, Jensen HK, Casao E, Civeira F, Gonzalez-Bonillo J, Rodriguez-Rey JC, Gregersen N and Pocovi M: Identification of recurrent and novel mutations in the LDL receptor gene in Spanish patients with familial hypercholesterolemia. Hum Mutat. Mutations in Brief \#135, online 11: 413, 1998.

15. Lombardi P, Hoffer MJ, Top B, De Wit E, Gevers Leuven JA, Frants RR and Havekes LM: An acceptor splice site mutation in intron 16 of the low density lipoprotein receptor gene leads to an elongated, internalization defective receptor. Atherosclerosis 104: 117-128, 1993.

16. Salazar LA, Hirata MH and Hirata RD: Increasing the sensitivity of single-strand conformation polymorphism analysis of the LDLR gene mutations in brazilian patients with familial hypercholesterolemia. Clin Chem Lab Med 40: 441-445, 2002.
17. Salazar LA, Hirata MH, Cavalli SA, Nakandakare ER, Forti N, Diament J, Giannini SD, Bertolami MC and Hirata RD: Molecular basis of familial hypercholesterolemia in Brazil: identification of seven novel LDLR gene mutations. Hum Mutat 19: 462-463, 2002.

18. Vella A, Pineda AA and O'Brien T: Low-density lipoprotein apheresis for the treatment of refractory hyperlipidemia. Mayo Clin Proc 76: 1039-1046, 2001.

19. Bilheimer DW: Portacaval shunt and liver transplantation in treatment of familial hypercholesterolemia. Arteriosclerosis 9 (suppl 1): I158-I163, 1989.

20. Khalifeh M, Faraj W, Heaton N, Rela M and Sharara AI: Successful living-related liver transplantation for familial hypercholesterolemia in the Middle East. Transpl Int 17: 735-739, 2005.

21. Shirahata Y, Ohkohchi N, Kawagishi N, Syouji M, Tsukamoto S, Sekiguchi S, Koyamada N, Oikawa S and Satomi S: Livingdonor liver transplantation for homozygous familial hypercholesterolemia from a donor with heterozygous hypercholesterolemia. Transpl Int 16: 276-279, 2003. 